Original Research Paper

\title{
Development and Cultivation of Local Kidney Bean (Phaseolus Vulgaris L) Through Breeding to use Multi gamma Irradiation Technique (Nuclear)
}

\author{
${ }^{1}$ Bartholomeus Pasangka and ${ }^{2}$ Refly \\ ${ }^{1}$ Department of Physical and Agricultural Sciences, \\ Faculty of Sciences and Technology, Nusa Cendana University, Kupang Indonesia \\ ${ }^{2}$ Department of Biology, Faculty of Science and Technology, Nusa Cendana University, Kupang Indonesia
}

Article history

Received: 25-04-2016

Revised: 21-09-2016

Accepted: 23-09-2016

Corresponding Author: Bartholomeus Pasangka Department of Physical and Agricultural Sciences, Faculty of Sciences and Technology, Nusa Cendana University, Kupang Indonesia

Email: bpasangka15@gmail.com

\begin{abstract}
Mutation on the all species of plant were generally caused by gamma or multi gamma radiation sources. The largest effect of that was occurred on chromosome and genetic factor, specially on structure and composition of chromosome and Deoxyribo Nucleic Acid (DNA). This case can be used for breeding of several important plants in Agricultural science. The objectives of this research is to develop of local kidney bean (Phaseolus Vulgaris L) that tolerant to dry condition and high production. Multi gamma radiation and selection are the main methods to use in this research and other methods comprised of observation/survey, sampling, comparison, analyzing and interpretation. The number of mutant varieties of kidney bean (superior seed of mutant) obtained in this research based on selection method are ten mutant varieties. The growth percentage rate, protein content of control and mutant variety of kidney bean were estimated respectively of $97,22.54$ and $24.21 \%$. The production of mutant kidney bean was between 3.97 tons/ha up to 5.28 tons/ha and the average production was 4.71 tons/ha. The average production of control was 2.60 tons $/ \mathrm{ha}$, in order that the production was significantly increased by $44.80 \%$.
\end{abstract}

Keywords: Breeding, Kidney Bean, Multigamma, Irradiation

\section{Introduction}

Mutation is a spontaneously changing process which occurred on genetic matter of an organism (called spontaneous mutation) and random and also through induce mutation (Soedjono, 2003). The abnormality on plant and other organism was irradiated by gamma or multi sources show the changing on genetic level or deoxyribo nucleic acid (DNA) and chromosome. Those process produce variations of new genetic as the basic of plant selection (natural or breeding), in order that, the breeder is easy to select of genotive apropriate to purpose of breeding (Gepts and Hancock, 2006; Agusrial, 2008; Carsono, 2008). On general, physical mutagent is high energy which produced by nuclear reaction from radioactive sources.

Theory of radiation effect there are two categories (Hollaender, 2002) i.e.: (1) Target theory or direct action theory. The biologists qualitatively and quantitatively investigate and explain the cell multiplication and mutation on the organism and around vital structure or molecular structure. They begin their investigation on outher morphology effect of organism, continuously to sensitive spot and vital structure (Handayani, 2009). The continuously research on citology and genetics obtained the changing in molecular structure. (2) Indirect action theory. This theory comes from chemicalists whose begin their investigation about radiation effect on act aspect of molecular and continued to macromolecular which cell composing, like as DNA, RNA, protein, etc for easy explaining of organism mutation.

\section{Radiation Effect Ionizes Nucleic-Acid and Nucleo- Protein}

The important components in chromosome support characterisric of generation are Nucleic-acid and nucleoprotein (Hollaender, 2002). The aberation of chromosome is caused by ionization energy disturbs of cell fission and mutaton. Multi gamma radiation produces depolarization and viscosity descent on Thymonucleic Acid (TNA), impedes syntesis of Deoxyribo Nucleic Acid (DNA). The several approaches 
of physics and biology have been done for illustrating of dosage limit and speed of low dossage. According to microdosimetry aspect, low dosage is smaller than $1 \mathrm{mGy}$, radiobiology: Low dosage is $20 \mathrm{mGy}$, epidemiology: Low dosage 200 mGy (UNSCEAR, 2005).

\section{Radiation effect on DNA and Chromosome}

DNA structure formed of double helicks which composed from bundle between phosphate group and dioxiribo sugar that form of strand DNA and bundle between nitrogen bases, which connect to two strands DNA. A large parts of DNA broken are occurred on bases broken, bases lost, the bundle between bases has broken and the bundle of sugar and phosphatehas broken, in order that, occurred broken on one strand is called single strand break $(s s b)$. This damage can be quickly reconstructed without mistake by enzymatic repairs process with using strand DNA that is not break as mold. Cell can do the contruction process to the DNA broken in a few hours, but can be not perfect, mainly to the broken of DNA is called double strends breaks $(d s b)$ (Brenner et al., 2006). The reconstruction process with mistaking causes mutaion of abnormality genetics and chromosome. The changing of chromosome structure is caused by gamma or multgamma radaition. Normally, chromosome comprises of upper-arm and fore-arm connected by a centromer. Multigamma radiation causes forming of: (1) assentric fragment (formed of chromosome fragment without centromer), (2) disentric chromosome (chromosome has two centromers), (3) ring chromosome, (4) translocation (removal of genetic matter betwen chromosome arm) (UNSCEAR, 2005).

According to IAEA statement (IAEA, 2008), mutation on the plant is spontaneously changes of genetic matters in cells caused by: (1) rearrangement occurred on chromosome structure, (2) changing in genetics, (3) segments duplication of chromosome loss. Radiation technique has several superiorities among others: (1) radiation technique is easy to do and practical, (2) the change of genotive a few only, but causes much changes of characteristics on generation species, (3) the generation species obtain in the short time.

Dose standard of gamma/multi gamma radiation is used on breeding of plants (IAEA, 2003; 2004; 2006): (1). Mutation on plants: $100 \mathrm{rads}$ up to $3,000 \mathrm{rads},(2)$. Mutation in seeds plant: 1,000 rads up to 4,000 rads, (3). Growth stimulation of seeds plant: 250 rads up to 1,000 rads, (4). Growth obstruction on root: 5,000 up to 10,000 rads (NNEA, 2005).

This research focused on development of local kidney bean from Manggarai Flores Indonesia with using multi gamma irradiation technique. In this method was obtained several variations of mutant, in order to easily selection of superior variety. The general characteristics of mutant of kidney bean variety are: (1) high production, (2) tolerant to dry conditions (Hartati, 2000), (3) the age of mutant is shorter, (4) tolerant to germ specially viruses (Radiyanto et al., 2011), (5) tolerant to plant disease like as Henose-pilachna signstipennis or Epilachna signatipennis, Etiella zickenella, Agromiza phaseoli, Aphis gossipi, Phytometra signata and P. calcites, Lamprosema indicata and $L$. diamenalis (Puryana and Mitra, 2008), (7) the quality of seed increase (content of protein and fat) (Irwan, 2006; NNEA, 2008). The development of local kidney bean in these research, uses multigamma radiation techniques. Multigamma radiation techniques lead of genetic effect such as the changes of structure and composition of chromosome and molecule of Deoxiribo Nucleat Acid (DNA) on several species of food plant.

Kidney bean is one kind of legumes that can grow at tropic and sub-tropic lowland up to altitude 2,000-2,500 $\mathrm{m}$ from sea level on temperatures 16 up to $27^{\circ} \mathrm{C}$ and rain fall $900 \mathrm{~mm}$ up to $1,500 \mathrm{~mm}$, air humidity 50 up to $60 \%$ (Rukmana, 2003). The average production of kidney bean until 2008 on national level was very low (only 1.2 tons/ha up to 2.13 tons/ha), just the opposite that the demand of consumer increase every year (Puryana and Mitra, 2008). The number of pods per tree is 8 up to 10 pods, the number of seeds per pod is 1 up to 3 and high plant is $15 \mathrm{~cm}$ up to $20 \mathrm{~cm}$. Kidney bean content of protein $(23,15 \%)$, folic acid, vitamin-B, folasin, tiamin, calcium, phosphor, iron and complex carbohydrate. The content of complex carbohydrate and fiber in kidney bean can decrease concentration of cholesterol in the blood (Puryana and Mitra, 2008; UNSCEAR, 2005).

The commodity production of kidney bean per hectare in Indonesia is not achieve maximum. That is influenced by soil factor, which damaged and is poor of micro-elements, growing hormone, dry conditions, germ, climate and the using of superior seeds (Puryana and Mitra, 2008).

These research aimed: To develop local kidney bean variety from Manggarai Flores Indonesia through breeding with aplication of multigamma radiation technique and carefully selection to obtain superior seed with high production and tolerant to dry condition.

Since 2010, researchers succeed to develop erect local penaut and creep local peanut from East Sumba with using multi gamma radiation. The increase of mean production $43.86 \%$ for creep local peanut and $42.22 \%$ for erect local peanut, or mean production 5.7 tons/ha (from 3.2 tons/ha up to 5.7 tons/ha) for creep local peanut, production potential 5.9 tons/ha and 4.5 tons/ha (from 2.6-4.5 tons/ha) for erect local peanut, production potential 4.7 tons/ha (Pasangka and Jaelani, 2011).

Since 2011, continuous research obtained production to be revolved between 4.75 tons/ha up to 6.84 tons/ha for creep local peanut and between 3.95 tons/ha up to 5.45 tons/ha for erect local peanut (Pasangka and Jaelani, 2011). 
Since 2012 up to 2014, researchers succeed to develop local soybean from Bajawa Flores Indonesia. The results of research are superior seed of mutant soybean with high production and tolerant to dry condition. There were ten varieties of superior seed of mutant were obtained from mutation by multi gamma radiation treatment. The production of mutant soybean (treatment sample) was 3.78 tons/ha up to 4.92 tons/ha, with mean production of 4.41 tons/ha. The mean production of control sample (initial soybean) was 2.54 tons/ha, with a significant increase of $42.40 \%$ (Pasangka and Refly, 2013).

\section{Materials and Methods}

\section{Material Studied}

The main instruments (Lab nuclear Physics Faculty of Sciences and Technology Nusa Cendana University) used in this research consist of: (1) Irradiator (Multi gamma radiation source: Co-60, Cs-137, Cd-109, Mn54 and Sn-113 in one kit), (2) counter of radiation dose (Radiolet-50 gamma counter type), (3) protein analyzer, (4) tractor, (5) other equipments. The sample for breeding is a local kidney bean from Manggarai Flores Island Indonesia with two groups: Control and treatment samples.

\section{Description Area}

The area of research is located in Kupang West Timor Island Indonesia, at five areas (the name of locations are: Fukdale, Naibonat, Baumata, Taibenu and Bakunase). All of those areas have the same conditions such as the high level of salt and calcium, dry condition, soil structure and illumination. The level of salt and calcium respectively are 2.86 and $22.62 \%$. The position of the area between $10^{\circ} 07$ ' $03.6^{\prime \prime}$ south latitude, $123^{\circ} 48^{\prime} 48.1^{\prime \prime}$ east longitude and $10^{\circ} 07^{\prime} 03.6^{\prime \prime}$ south latitude, $123^{\circ} 49^{\prime}$ '57.4" east longitude on $96 \mathrm{~m}$ altitude (96 $\mathrm{m}$ from sea level). The average illumination of the area is $5 \mathrm{~h}$ per day.

\section{Methods}

The main methods of research consist of: Obsrvation/surveying, sampling, radiation, selection, comparison and interpretation. Collecting and data analysis are done with observation, measurement, protein analysis on initial kidney bean and also on treatment sample (mutant). Quality control is done to compare between physical and chemical characteristics of control sample (initial kidney bean) and treatment sample (mutant) that obtained from observation, measurement and calculation.

\section{Procedures of Research}

The procedures of this research consist of: (1) to choose research location and sample of local kidney bean, (2) to prepare research location, (3) to irradiate samples of kidney bean seeds as long as one hour, (4) to plant sample of kidney bean in the prepared area. The conditions of prepared area are specified to be based on data from department of agricultural, i.e.: The level of salt and calcium respectively are 2.86 and $22.62 \%$, (5) watering if it is necessary, (6) weeding and cultivating, (7) observation to tenacity of germ, growth in dry area, high calcium and salt and physical characteristics which were needed for a standard comparison i.e., growth time, flowered age, tenacity of germ, adaptation, growth percentage, mass per 1,000 seeds, maximum production potential, mean production and also select plants. On the resemble harvest, is done selection, measurement of high plant, in time after harvest is measured of mass for a group of 1,000 kidney bean seeds, (8) to analyze protein (service analysis model), (9) drying and selection. The drying conditions is take time from 06,30 a. m until to 9,30 a. m, (10) For quality control is done comparison between physical and chemical characteristics of control sample (initial kidney bean) and treatment sample (mutant), that obtained from observation/survey, measurement and calculation, (11) The last procedure is to put insecticide sufficient to mutant (superior seeds of kidney bean), so to be spared from pest and or germ and storage for continuously development. The first selection of kidney bean plant is done since the age of plant is one month, the second selection since the age of plant two months, $\mathrm{M}_{0 \mathrm{n}}$ selection since near to harvest and the third selection after harvest.

\section{Observes and Measures}

The amount of physical characteristics of kidney bean (Control sample and mutant) during growth and after harvest was observed and measured like as adaptation, tenacity of germ, grow time, flower age, the length of plant and weight per 1,000 seeds, protein content, potential production and mean production. In this case were selected 100 plants of each variety for measuring. Table 1 contain any informations about the important physical and chemical characteristics of kidney bean and Table 2 special contain production level, average production, leaf ranges and root of control and treatment samples. Table 3 special contain of Data for evaluating of growth percentage rate (the number of seeds was not grown on the control sample and treatment sample). The calculation result of data in Table 3 also included in Table 1.

\section{Research Design}

The samples of local kidney bean were chosen with two groups, i.e., control (initial kidney bean) and treatment samples. The treatment sample (seeds of kidney bean) was irradiated by multigamma sources on radiation dose 3.500 rads. The samples were planted in 
the same time and location. The time planting is started from 06.00 a. $\mathrm{m}$ until to 09.00 a. $\mathrm{m}$ and all locations have the same conditions like as level of salt and calcium, dry condition, the same altitude $(96 \mathrm{~m}$ from sea level). Three plant selections were done according to the research design on Fig. 1. The first selection of kidney bean plant was done since the age of plant was one month, the second selection since the age of plant was two months, $\mathrm{M}_{0 \mathrm{n}}$ selection since near to harvest and the third selection after harvest.

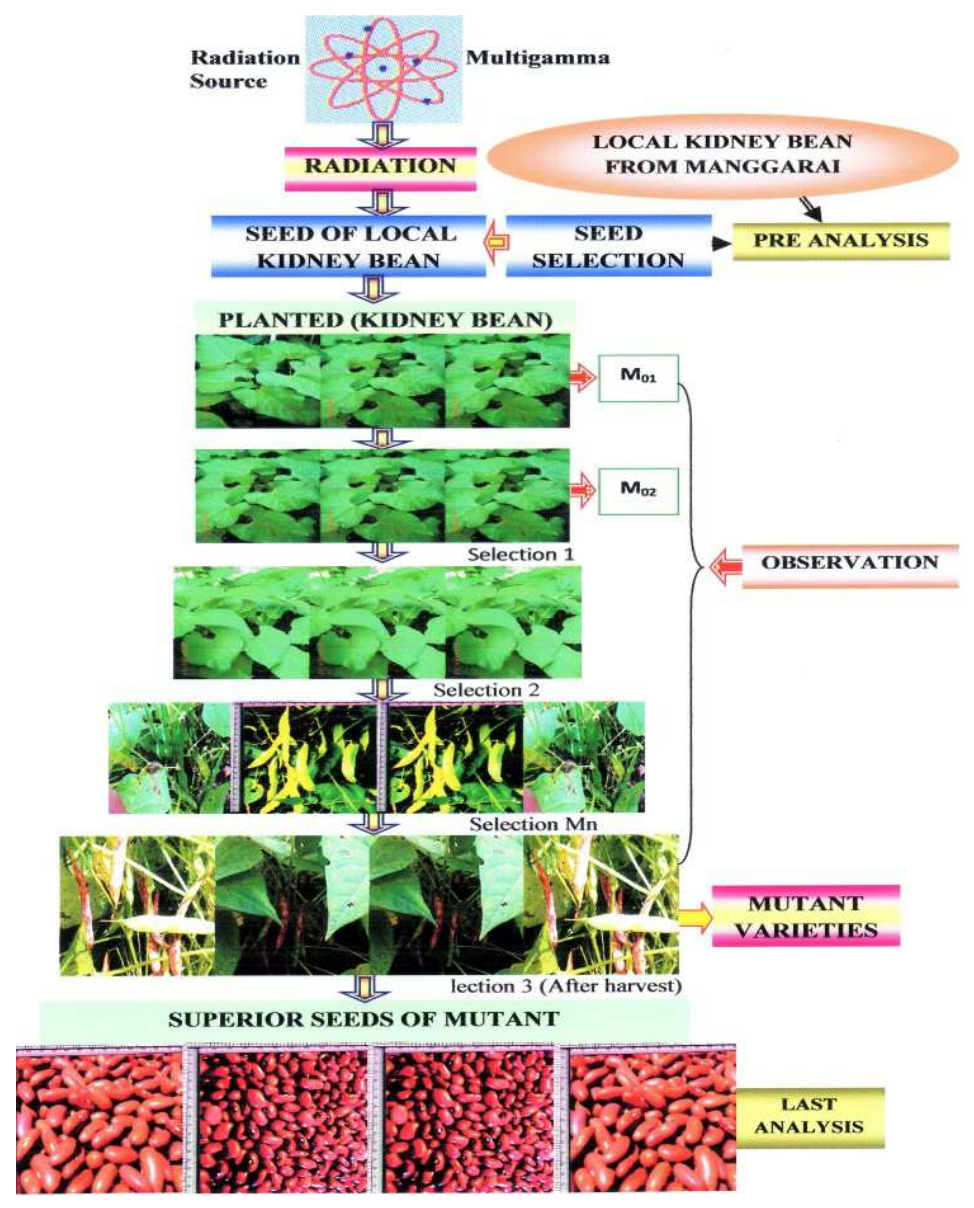

Fig. 1. Research design

Table 1. The important physical and chemical characteristics were observed, measured and calculated of kidney bean on control sample and treatment sample

\begin{tabular}{lll}
\hline Description & $\begin{array}{l}\text { Control sample of kidney } \\
\text { bean (Initial Variety) }\end{array}$ & $\begin{array}{l}\text { Mutant kidney bean ( Treatment } \\
\text { sample or generation Variety) }\end{array}$ \\
\hline Grow time & 9 days after planted (dap) & 5 dap \\
Flowered age & 68 dap & 45 dap \\
The average high of plant & $41.23 \mathrm{~cm}$ & $67.40 \mathrm{~cm}$ \\
Tenacity of germ & Not tenacity & Tenacity \\
Adaptation & Adaptation to area with high & Adaptation to area with high \\
& calcium and salt. & $97 \%$ \\
Growth percentage rate & $80 \%$ & 73 days after planted (dap) \\
The age of plant & 105 days after planted (dap) & $24.21 \%$ \\
Protein content & $22.54 \%$ & $5-22$ (average: 16$)$ \\
The number of pods per tree & $4-10$ (average: 6$)$ & $2-7$ \\
The number of seeds per pods & $1-4$ & 543.70 grams \\
Mass per 1,000 seeds & 374.88 grams & 3.97 tons $/$ ha -5.28 tons $/$ ha \\
Production range & 2.46 tons/ha -2.81 tons $/$ ha & 5.28 tons $/$ ha \\
Maximum production potential & 2.81 tons/ha & 4.71 tons $/$ ha \\
The average production & 2.60 tons/ha &
\end{tabular}


Table 2. Production level at several planting locations of kidney bean (Control and treatment samples) Control sample Treatment sample (Mutant)

\begin{tabular}{|c|c|c|c|c|c|c|c|c|}
\hline $\begin{array}{l}\text { Planting } \\
\text { location } \\
\text { (1 hectare) }\end{array}$ & $\begin{array}{l}\text { Leaf } \\
\text { ranges } \\
\text { (stems) }\end{array}$ & Root & $\begin{array}{l}\text { Production } \\
\text { level } \\
\text { (tons/ha) }\end{array}$ & $\begin{array}{l}\text { The average } \\
\text { production } \\
\text { (tons/ha) }\end{array}$ & $\begin{array}{l}\text { Leaf } \\
\text { ranges } \\
\text { (stems) }\end{array}$ & Root & $\begin{array}{l}\text { Production } \\
\text { level } \\
\text { (tons/ha) }\end{array}$ & $\begin{array}{l}\text { The average } \\
\text { production } \\
\text { (tons/ha) }\end{array}$ \\
\hline Fukdale $\left(\mathrm{P}_{1}\right)$ & & Adventiti- & 2.81 & & & Adventiti- & 5.28 & \\
\hline Naibonat $\left(\mathrm{P}_{2}\right)$ & & Ous root, & 2.54 & & & Ous root, & 4.96 & \\
\hline Baumata $\left(\mathrm{P}_{3}\right)$ & $5-7$ & Large & 2.52 & 2.60 & $6-10$ & Large & 4.23 & 4.71 \\
\hline Taibenu $\left(\mathrm{P}_{4}\right)$ & & Straight & 2.69 & & & Straight & 5.12 & \\
\hline Bakunase $\left(\mathrm{P}_{5}\right)$ & & Root & 2.46 & & & Root & 3.97 & \\
\hline
\end{tabular}

Table 3. Data for evaluating of growth percentage rate (the number of seeds was not grown on the control sample and treatment sample or mutant of kidney bean)

\begin{tabular}{llll}
\hline $\begin{array}{l}\text { Sample } \\
\text { Group }\end{array}$ & $\begin{array}{l}\text { Total number of seeds } \\
\text { every group }\end{array}$ & $\begin{array}{l}\text { Control Sample } \\
\text { Number of seeds was not grown }\end{array}$ & $\begin{array}{l}\text { Mutant (treatment sample) } \\
\text { Number of seeds was not grown }\end{array}$ \\
\hline I & 100 & 18 & 4 \\
II & 100 & 17 & 1 \\
III & 100 & 24 & 5 \\
IV & 100 & 19 & 2 \\
V & 100 & 22 & 1 \\
Mean & 100 & 20 & 3 \\
\hline
\end{tabular}

\section{Statistical and Data Analysis}

Statistical formula was needed to calculate of growth percentage rate and percentage of increasing of mean production. For testing of growth percentage rate, we choose five samples groups at random on control and treatment sample. The number of test sample is 100 seeds on every group. The number of seeds sample was not grown to be observed. The growth percentage rate was calculated by equation (Pasangka, 2015):

$G P=\left(\frac{T_{S G}-N_{S N}}{T_{S G}}\right) \times 100 \%$

Where:

$G P=$ Growth percentage rate $(\%)$

$T_{S G}=$ Total number of seeds to be planted (prepared sample)

$N_{S N}=$ The number of seeds was not grown

$\mathrm{M}_{0 \mathrm{n}}$ selection is done on several good plants with different superior characteristics, but same production and adaptation, for example: $\mathrm{M}_{02}$ and $\mathrm{M}_{05}$ on Fig. 4, have the same mean production, but different color of seed and high of plant. High of plant on $\mathrm{M}_{02}$ is 64.45 $\mathrm{cm}$ and high of plant on $\mathrm{M}_{05}$ is $67.25 \mathrm{~cm}$. The growth of the both plant $\left(\mathrm{M}_{02}\right.$ and $\left.\mathrm{M}_{05}\right)$ is strong. $\mathrm{M}_{0 \mathrm{n}}$ is selected at the each planted location with the each $\mathrm{M}_{0 \mathrm{n}}$ group have same superior characteristics like as mass per 1000 seeds, high of plant, the number of pods per tree, etc.

Equation formula for calculating percentage of increasing of mean production was:

$$
P_{i}=\left(\frac{M_{P}-M_{C}}{M_{P}}\right) \times 100 \%
$$

Where:

$P_{i}=$ Percentage of increasing of mean production

$M_{P}=$ Mean production of mutant

$M_{c}=$ Mean production of control

Mean production was calculated by equation formula:

$M_{c}=\frac{P_{1}+P_{2}+P_{3}+P_{4}+P_{5}}{5}$

where, $P_{i}, P_{2}, P_{3}, P_{4}, P_{5}$ are production at 5 locations.

Protein content is calculated by equation:

$P P C=\frac{(B-E) \times N N a O H \times 0.014}{m} \times 100$

Where:

$P P C=$ Percentage of protein content

$B=$ Blank

$E \quad=$ Example

$m$ = Mass of sample of kidney bean (control sample and treatment sample).

Flowered rate percentage can be calculated by formula:

$F R P_{i}=\left(\frac{F A C S-F A T S}{F A C S}\right) \times 100 \%$

Where:

$F R P=$ Flowered rate percentage

$F A T S=$ Flowered age of treatment sample

$F A C S=$ Flowered age of control sample 
The increasing percentage of mass per 1,000 seeds can be calculated by equation:

$$
P_{m}=\left(\frac{M P T S-M P C S}{M P T S}\right) \times 100 \%
$$

Where:

$P_{m} \quad=$ Increasing percentage of mass per 1,000 seeds MPTS = Mass per 1,000 seeds of treatment sample $M P C S=$ Mass per 1,000 seeds of control sample

The increasing percentage of mean pods per tree is calculated by equation:

$$
I P P P=\left(\frac{M P P T S-M P P C S}{M P P T S}\right) \times 100 \%
$$

Where:

$I P P P=$ The increasing percentage of mean pods per tree

MPPTS $=$ The number of pods on treatment sample

$M P P C S=$ The number of pods on control sample

\section{Calculating}

Based on equation (1), growth percentage rate of seeds on control sample and mutan can be determined. Growth percentage rate of control sample:

$$
G P=\left(\frac{T_{S G}-N_{S N}}{T_{S G}}\right) \times 100 \%=\left(\frac{100-20}{100}\right) \times 100 \%=80 \%
$$

Growth percentage rate of mutant:

$$
G P=\left(\frac{T_{S G}-N_{S N}}{T_{S G}}\right) \times 100 \%=\left(\frac{100-3}{100}\right) \times 100 \%=97 \%
$$

The percentage of increasing of mean production was determined by Equation 2, i.e.:

$$
P_{i}=\left(\frac{M_{P}-M_{C}}{M_{P}}\right) \times 100 \%=\left(\frac{4.71-2.60}{4.71}\right) \times 100 \%=44.80 \%
$$

Mean production of control sample:

$$
\begin{aligned}
& M_{c}=\frac{P_{1}+P_{2}+P_{3}+P_{4}+P_{5}}{5} \\
& =\frac{2.81+2.54+2.52+2.69+2.46}{5}=2.60 \text { tons } / \text { ha }
\end{aligned}
$$

Mean production of mutant (treatment sample):

$$
\begin{aligned}
& M_{P}=\frac{P_{1}+P_{2}+P_{3}+P_{4}+P_{5}}{5} \\
& =\frac{5.28+4.96+4.23+5.12+3.97}{5}=4.71 \text { tons } / \mathrm{ha}
\end{aligned}
$$

Protein content:

$$
P P C=\frac{(B-E) \times N N a O H \times 0.014}{m} \times 100 \%
$$

Note: Protein content is direct calculated in protein analyzer as many as $22.54 \%$ for control sample (initial kidney bean) and $24.21 \%$ for treatment sample (mutant).

Flowered rate percentage:

$$
F R P_{i}=\left(\frac{68-45}{68}\right) \times 100 \%=33.83 \%
$$

The increasing percentage of mass per 1,000 seeds:

$$
\begin{aligned}
& P_{m}=\left(\frac{M P T S-M P C S}{M P T S}\right) \times 100 \% \\
& =\frac{543.70-374.88}{543.70} \times 100 \%=31.03 \%
\end{aligned}
$$

The increasing percentage of mean pods per tree:

$$
I P P P=\left(\frac{16-6}{16}\right) \times 100 \%=62.50 \%
$$

\section{Result and Discussion}

\section{Observes and Measures}

The important physical and chemical characteristics were observed and measured of kidney bean on control sample and treatment sample (Mutant) included in Table 1 and the production level at the several planting locations of local kidney bean on control and treatment samples incuded in Table 2.

Figure $2 \mathrm{a}, 2 \mathrm{c}$ and $2 \mathrm{e}$ shows three examples of the physical growth of control samples (initial local kidney bean from Manggarai Flores Indonesia) and the physical growth of mutant (variety of kidney bean was obtained from mutation by multigamma radiation or treatment sample) were shown on Fig. 2 b, $2 \mathrm{~d}$ and $2 \mathrm{f}$.

The Fig. 2 shown that the growth (Fig. 2a control sample and Fig. 2b treatment sample) and fruits between control and treatment sample is significantly differenced with an important amounts of fruits has been observed for the treatment sample (Fig. 2d) compared to the control sample (Fig. 2c) and it's clearly that the Fig. $2 f$ (treatment sample) has many fruits than Fig. 2e (control sample). 


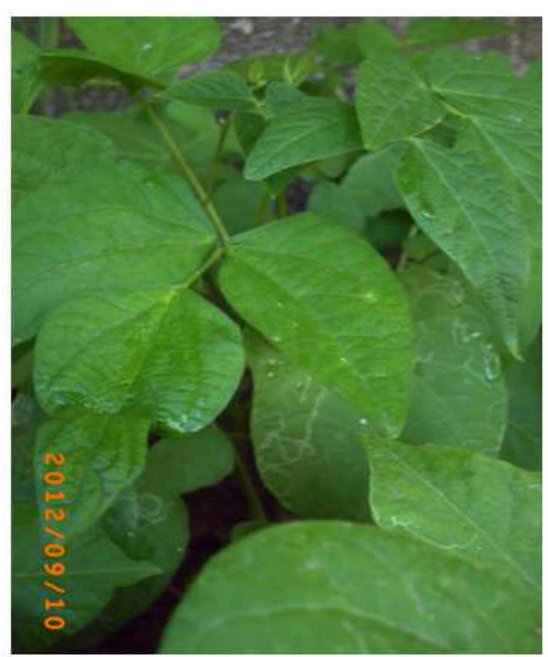

(a)

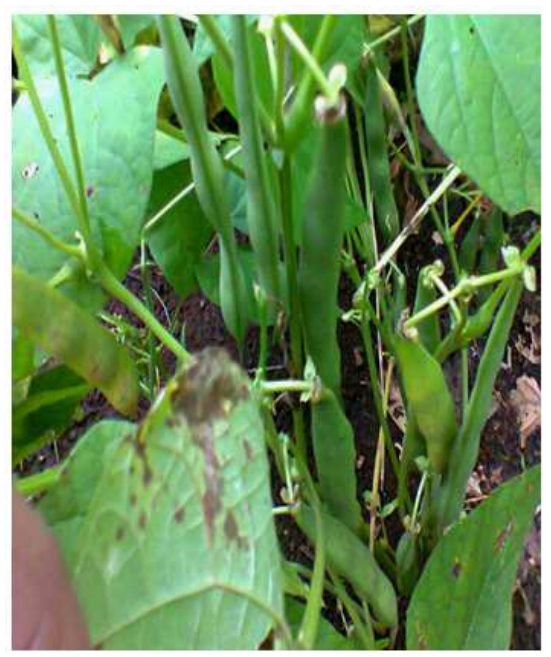

(c)

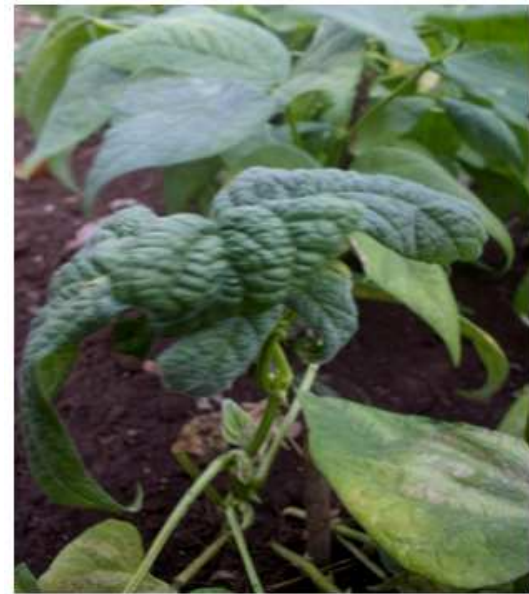

(e)

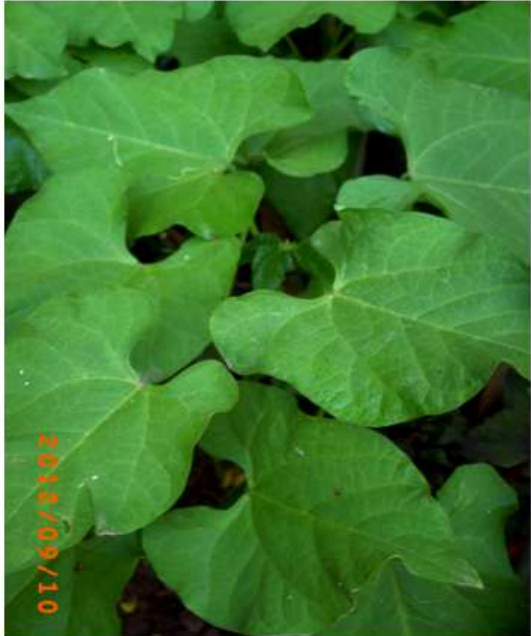

(b)

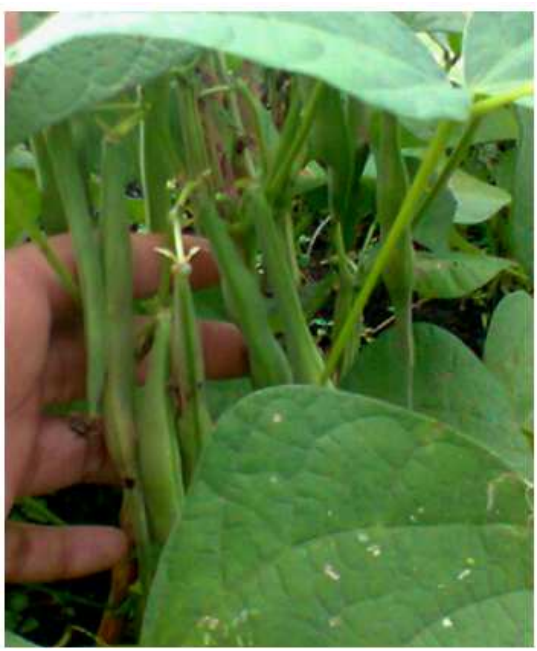

(d)

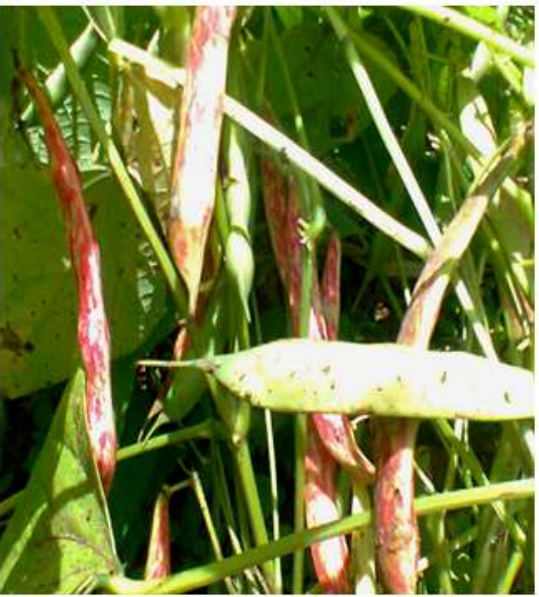

(f)

Fig. 2. Figure 2a-e show three examples of the physical growth of control samples and Figure $2 \mathrm{~b}-\mathrm{f}$ show three examples of the physical growth of mutant (result from multi gamma radiation), (a) Control sample, (b) Treatment sample (irradiated by 3500 rads), (d) Control sample, (c) Treatment sample, (e) Control sample, (f) Treatment sample 


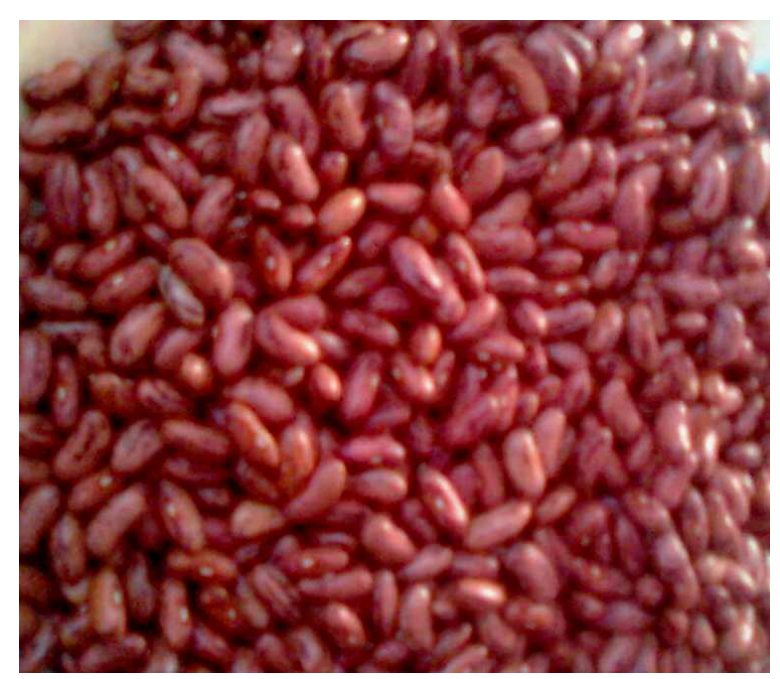

Fig. 3. The seeds of control sample (seeds of initial kidney bean)

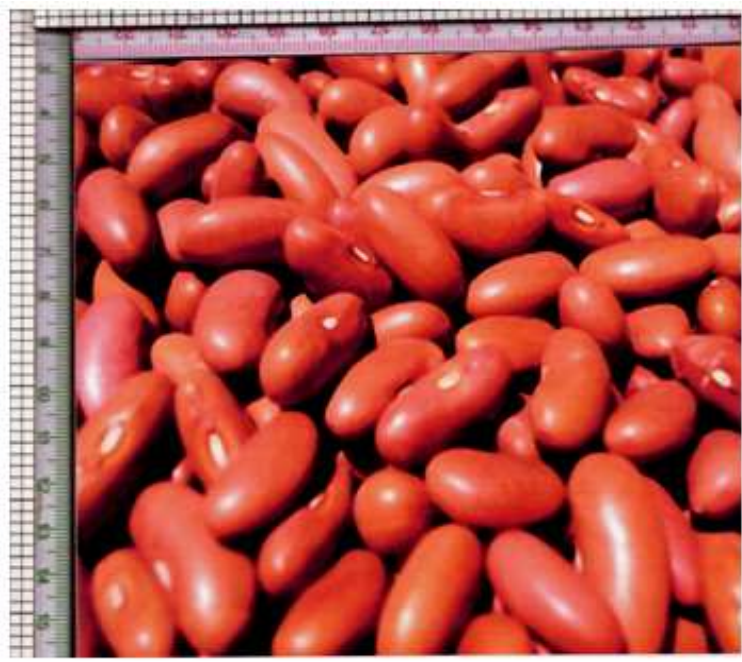

(a)

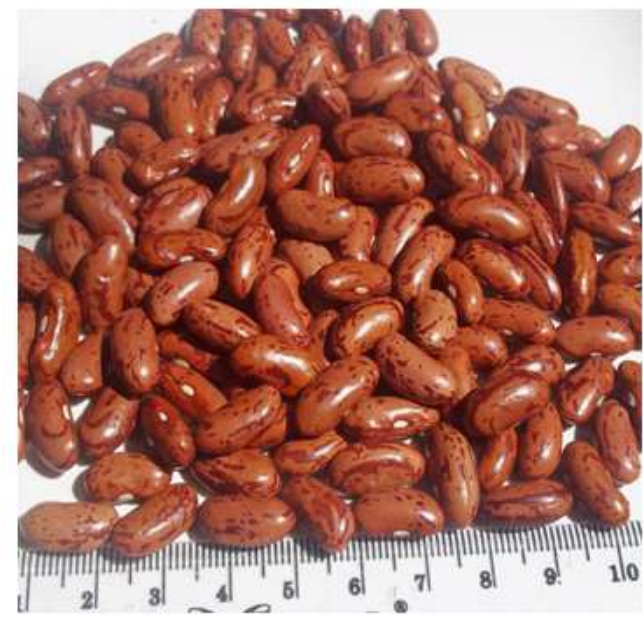

(b)

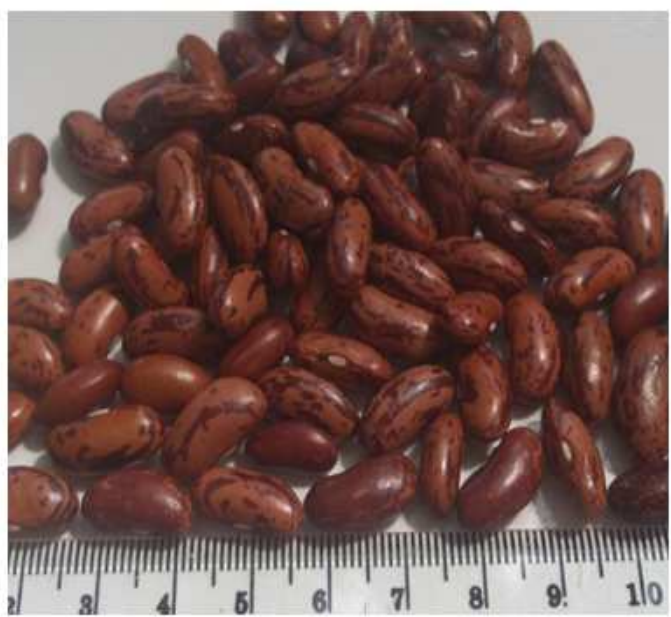

(c)

Fig. 4. Three examples of mutant seed varieties were obtained from muation by multigamma radiation, (a) Mutant-1 variety of kidney bean, (b) Mutant-2 variety of kidney bean, (c) Mutant-3 variety of kidney bean 
Table 4. The physical and chemical characteristics of the ten mutant varieties were observed and measured

\begin{tabular}{lllllllllll}
\hline Description & M01 & M02 & M03 & M04 & M05 & M06 & M07 & M08 & M09 & M010 \\
\hline High of plant (cm)* & 64,17 & 64,45 & 65,78 & 66,12 & 67,25 & 67,86 & 68,19 & 68,84 & 70,21 & 71,13 \\
The age of plant* (days) & 68 & 68 & 70 & 72 & 73 & 75 & 75 & 76 & 76 & 77 \\
The number of pods per tree* & 22 & 18 & 18 & 18 & 15 & 15 & 15 & 14 & 13 & 12 \\
The number of seeds per pod* & 3 & 4 & 4 & 4 & 5 & 5 & 5 & 6 & 7 & 7 \\
& Wine & & & & Dark & Bright & & & Wine & \\
Color of seed* & colored & Brown & Brown & Pink & red & red & Pink & Pink & colored & Brown \\
Mass per 1,000 seeds* & 546.10 & 545.80 & 545.76 & 545.24 & 543.62 & 543.30 & 543.18 & 542.36 & 541.14 & 540.50 \\
Adaptation to dry condition* & yes & yes & yes & yes & yes & yes & yes & yes & yes & yes \\
Adaptation to germ* & yes & yes & yes & yes & yes & yes & yes & yes & yes & yes \\
\hline
\end{tabular}

Figure 3, shows one example of seeds of control sample and Fig. 4a up to Fig. 4c, show three examples of mutant (mutant seeds of kidney bean was obtained from mutation by multigamma irradiation with ten varieties). Mutant-1 up to mutant-3 on Fig. 4, were obtained by a carefully selection. Selection is done appropriate to several important physical and chemical characteristics like as production level, age of plant, mass of a group 1,000 seeds, high of plant, flowered age and other characteristics.

The number of seeds was not grown on the control sample and mutant were included in Table 3 and the physical and chemical characteristics of the ten mutant varieties were observed, measured and calculated were included in Table 4. The varieties of mutant $\mathrm{M}_{0 \mathrm{n}}$ or groups of $\mathrm{M}_{01}$ up to $\mathrm{M}_{010}$ are called the first generation or $\mathrm{M}_{1}$. The second, the third, etc generation or $\mathrm{M}_{2}, \mathrm{M}_{3}$, $\ldots \mathrm{M}_{\mathrm{n}}$, will be obtained on the next research, for this reason will be carefully selected on the second, third, etc planted on groups $\mathrm{M}_{10}, \mathrm{M}_{11}, \mathrm{M}_{12}, \ldots \mathrm{M}_{1 \mathrm{n}}, \mathrm{M}_{20}, \mathrm{M}_{21}, \mathrm{M}_{22}$, .. $\mathrm{M}_{2 \mathrm{n}}$, etc. The second research will be examined homogeneous of mutant and the third research will be examined multi location, homogeneous of mutant and tolerant to dry condition and germ.

Data in Table 3 show the five groups of control and treatment samples for evaluating of growth percentage rate. The average number of seeds was not grown on control and treatment samples respectively were twenty seeds and three seeds. This case shows that the calculating result of growth percentage rate of control sample and treatment sample were 80 and $97 \%$.

Data in Table 4 show the physical and chemical characteristics of the ten mutant varieties were observed and measured. The calculation result based on data in Table 4, give the average: High of plant, age of plant, number of pods per tree, number of seeds per pod and mass per 1,000 seeds respectively were $67.40 \mathrm{~cm}, 73$ days, 16 pods, 5 seeds and 543.70 grams.

The Time Growth of Seeds, Growth Percentage Rate, Flowered Age and other Characteristics

The seeds of control sample (initial kidney bean) need 9 days to grow and less required time for the treatment sample (mutant), which was estimated of 5 days after planted (dap) and since the age is 8 days, the growth of sprout is $97 \%$ and the age of harvest on treatment sample (mutant) is 73 dap. This case shows that the treatment samples (mutant) grow faster than control sample (without irradiation). So, can be proposed that the treatment sample (mutant) has age is the short time compared to control sample (105 dap). The control sample is flowered on 68 days after planted (dap) and flowered age of treatment sample (mutant) is 45 days after planted (dap). Thus, clearly show that the treatment sample is flowered faster than control sample (is faster than $33.83 \%$ ). The control sample was adapted to area with high calcium and salt and the mutant varieties or treatment sample of kidney bean was adapted to area with high calcium, salt and dry condition. The growth percentage rate of control sample (initial kidney bean) is $80 \%$ and the treatment sample (mutant) is $97 \%$.

\section{The Range Production, Average Production, Increase of Mean Production and Adaptation, Fertilizing}

The mean or average mass of 1,000 seeds of control sample (initial kidney bean) is 374.88 grams and mutant sample is 543.70 grams. The increasing percentage of mass per 1,000 seeds is $31.03 \%$. The increasing percentage of mean pods per tree is $62.50 \%$. The range production of control sample (initial kidney bean) is 2.46 tons/ha up to 2.81 tons/ha and treatment sample (mutant) is 3.97 tons/ha up to 5.28 tons/ha. The maximum production potential of control sample is 2.81 tons/ha, with average production 2.60 tons/ha and mutant variety is 5.28 tons/ha with average production 4.71 tons/ha. Those data show that physical and chemical characteristics of mutant are superior than control sample (initial kidney bean). All of these characterictics were clearly different. The ten varieties of primer seed or superior seed were obtained from mutation by multigamma radiation and carefully selection. The improved traits stably inherited in the later generation of those varieties of soybean (10 varietes) will be tested on continuosly research. NNEA gives report that the mean production of kidney bean only 4,10 tons/ha and can be adapted to area with high calcium but was not adapted to dry conditions (NNEA, 2008). In other researchs (Pasangka and Jaelani, 2011; 2013) on corn, peanut and 
soybean breeding, they found that the generations of those plants have the traits stably inherited up to 7 generations and after that the production to be more decreased. Agricultural land in Kupang Timor Island Indonesia was dominated by soil with high calcium, high salt and dry condition and also germ. It's necessary to develop plants that will be able to adapt in those conditions. Figure $4 \mathrm{a}$ up to $4 \mathrm{c}$, show three examples of mutant seeds of kidney bean. Kidney bean seeds on: Figure $4 \mathrm{a}$, tolerant to germ, dry condition and area is high calcium and salt, Fig. $4 \mathrm{~b}$ tolerant to germ, dry condition and area is high calcium, Fig. 4c, tolerant to germ, dry condition and area with high calcium. The control sample is not tolerant to dry conditions, only adapt to high calcium and salt.

Contain of Nitrogen in soil on research location was not enough for good growing of plant (17\%). According to International standard, this value was low $(<10 \%$ was very low, $10-21 \%$ was low, $22-51 \%$ was medium, 52$75 \%$ was high, $>75 \%$ was very high, Rukmana 2003 ) Because of that, fertilizing was done when the age of plant (kidney bean) about 24 days (before flowered) to use NPK (Nitrogen-Phosphorous-Potassium) and Urea. Concentration of Nitrogen in Urea was $46 \%$. The quantity of fertilizing used was 100 kilograms/ha NPK and $100 \mathrm{kilograms} / \mathrm{ha}$ Urea. It was enough for good growing of plant. It was appropriate with previous research (Rukmana, 2003).

\section{Tenacity to Germ}

Based on observations from first growth until to harvest time or during growth of plant was shown clearly that growth of treatment sample of kidney bean (mutant) tenacity to germ. In this case is shown by soft leaf since growth of kidney bean. This argument clearly shown on Fig. 2e (control sample) and Fig. 2f (treatment sample or mutant). The plant on Fig. 2e has not fruit and it's leaf wrinkled because attacked by germ. According to the research result from Radiyanto et al. (2011), the kidney bean is not tenacity to several germs like as Aphis glycine, Riptortus Linearis, Sclerotium Rolfsii, Phachyrizi Phakospora and Xanthomonas Phaseoli.

\section{The Containing of Protein}

Protein content of control sample and treatment sample (mutant) respectively were 22.54 and $24.21 \%$. According to literature (previous research), protein content of control sample is $23.15 \%$ (Puryana and Mitra, 2008; UNSCEAR, 2005).

\section{Root, Leaf, Soil Condition, Temperature, Rainfall and Humidity}

Generally, kidney bean has the adventitious root and large straight root with shallow lateral branching. The root strengthen on the growth of plants, transport of water and the other elements to the all parts of plants.
The first joints of plant (nodus) on pre growth formed pair of single leaf (Fig. 2b) and continuous on the all joints formed compound of leaf with three leaves. The form of leaf was oval, thin and green color. Leaf surface has soft feather (trachoma) on the both side. The flowers growth on the armpit of compound leaf stalks.

Based on observation result and previous research, the kind of soil at research location was andosol and regosol. The average of research location altitude was $2,100 \mathrm{~m}$ from sea level. According to previous research, kidney bean good growth on altitude $(2,000-2,500)$ meters from sea level and the kind of soil was regosol and andosol (Rukmana, 2003). Characteristics of andosol soil were black color, clay to dust texture, loose and medium permeability (Rukmana, 2003). Characteristics of regosol soil were gray and yellow color, send texture and permeable.

The variation of temperature at the research location was $18-28^{\circ} \mathrm{C}$ on the planting climate. The average temperature of five research locations was $24^{\circ} \mathrm{C}$. Previous research reports that the ranges temperature for good growth of kidney bean was $20-25^{\circ} \mathrm{C}$ (Rukmana, 2003).

The average rainfall at the research location was $1,650 \mathrm{~mm} /$ year. According to previous research, kidney bean can good growth on rainfall between $(1,500-2,500)$ $\mathrm{mm} /$ year (Rukmana, 2003). The variation of humidity at the research location was $(48-64 \%)$. This reason, on humidity between $((70-80 \%)$, the several aphids can be more past breed.

Based on data in Table 1, 2 and 4: Data calculations, observation and explanation above can be suggested any arguments that mutant that more quickly plowered, more fertile, mass per 1,000 seeds is higher, growth rate percentage is higher than control, which was adapted to germ, dry condition, high calcium, high salt, the mean or average production is higher. The mean production of control sample (initial variety) is 2.60 tons/ha and mean production of mutant (generation variety) is 4.71 tons/ha. This result shows that mean production of mutant of local kidney bean from Manggarai Flores Indonesia was increased significantly. The increase of mean or average production is $44.80 \%$.

\section{Conclusion}

Based on explanation upon can be proposed that development of local kidney bean from Manggarai Flores Indonesia by irradiation with using multi gamma radiation source and carefully selection was obtained mutant seeds of kidney bean with physical and chemical characteristics was superior for continuously development. The range production of mutant was obtained from mutation by irradiation with using multi gamma radiation was 3.97 tons/ha up to 5.28 tons/ha, mean or average production was 4.71 tons/ha and the 
increase of mean production was $44.80 \%$. The treatment samples selected were tolerant to area with dry conditions, high calcium and salt and tenacity to germ.

\section{Acknowledgement}

This research or study was supported and funded by Decentralization research, Directorate of Reseach and Public Service, Department of Education and Culture of Indonesia Goverment, 2015/2016. Special thanks to Government of Indonesia has been funded of this research and also special thanks to all colleagues in English Training Centre, Whom have helped to me in technical writing of this manuscript.

\section{Author's Contributions}

The all authors have contributions of this manuscript like as collaborated on research and always to be discussed for writing manuscript.

\section{Conflict of Interest}

This work is funded by Decentralization research, Directorate of Reseach and Publc Service, Department of Education and Culture of Indonesia Goverment, 2015/ 2016. The publication fee is included in this financial.

\section{References}

Agusrial, 2008. The breeding of plant with nuclear technique.

Brenner, D.J., E.J. Hall and R.K. Sachs, 2006. Are Bystander Effects Important at Low Radiation Dose? Proceedings of the Conference of Radiation Effects, (CRE' 06), Washington, DC.

Carsono, N., 2008. The benefit of plant breeding for increasing of agricultural production in Indonesia. J. Nat. Inst. Agro-biologicao Sci.

Gepts, P. and J. Hancock, 2006. The future of plant breeding. J. Biotech Crop Sci., 1: 18-23. DOI: $10.2135 /$ cropsci2005-12-0497op

Handayani, 2009. Analysis of morphology and molecular of soybean tolerant to low intensity of light. J. Sci. Technol. Indonesia.

Hartati, S., 2000. The genotive appearance of tomato as a result of mutation on water stress conditon and optimal condition. J. Agrosciences, 2: 12-16.

Hollaender, A., 2002. Radiation Biology. McGraw-Hill Book Company, Inc, New York.
IAEA, 2003. Rice breeding with induced mutation. J. Tech. Reports Series, 125: 95-102.

IAEA, 2004. Radiation safety of gamma and electron irradiation facilities. J. Safety Series, 101: 71-98.

IAEA, 2006. Preservation of fruit and vegetables by radiation. J. Safety Standard Series, 103: 75-93.

IAEA, 2008. Case studies in the application of probabilistic safety assessment techniques to radiation sources. Final Report Coordinated Res. Project, 1494: 27-41.

Irwan, A.W., 2006. The Cultivation of Glycine Max L Merill. Agricultural Cultivation, UNPAD Jatinangor.

NNEA, 2005. Doses limit system, nuclear technology center and radiometry, national nuclear energy agency. Journal Science and Nuclear Technology, Vol 1. No. 2, pp: 1-6, Bandung Indonesia.

NNEA, 2008. The new superior variety of kidney bean as a result of breeding thrugh mutation of radiation. J. Atomos Inform. Media Sci. Nuclear Technol., 1: 1-8.

Pasangka, B. and A.K. Jaelani, 2011. The development of local peanut with multi culture based that tolerant to abiotic and biotic conditions through breeding by multi gamma radiation (Nuclear). J. Reearch Develop. Bulletin, 10: 44-61.

Pasangka, B. and Reffly, 2013a. The application of multi gamma radiation as a physical mutagen for breeding of local soybean. J. Agric. Sci., 5: 201-210.

Pasangka, B. 2015. Cultivation of Soybean as a Result of Genetics Engineering with Nuclear Technique (Multi gamma Irradiation), Reference Book.

Puryana and D. Mitra, 2008. The growth of kidney bean in the different medium. SMK Purbalingga Indonesia.

Radiyanto, B., Mochammad Saliq and N.M. Nurcahyani, 2011. Germ insect diversity on kidney bean. J. Entomol. Indonesia, 8: 8-13.

Rukmana, R., 2003. Cultivation of kidney bean. Yogyakarta Indonesia, Kanisius.

Soedjono, S., 2003. The application of induce mutation and variation in plant breeding. J. Agric. Sci., 1: 35-40.

UNSCEAR, 2005. Continuously report to the general assembly. United Nations Scientific Committee on the Effects of Atomic Radiation, New York. 